\title{
Endoscopic approach to biliary diseases in 2020: Is there still a role for direct peroral cholangioscopy?
}

\section{(1) $\circledast \odot$}

\author{
Author \\ Torsten Beyna

\section{Institution} \\ Department of Gastroenterology and Therapeutic \\ Endoscopy, Evangelisches Krankenhaus Düsseldorf, \\ Germany
}

\section{Bibliography}

Endosc Int Open 2021; 09: E1453-E1455

DOI 10.1055/a-1339-1338

ISSN 2364-3722

(c) 2021. The Author(s).

This is an open access article published by Thieme under the terms of the Creative Commons Attribution-NonDerivative-NonCommercial License, permitting copying

\author{
and reproduction so long as the original work is given appropriate credit. Contents \\ may not be used for commercial purposes, or adapted, remixed, transformed or \\ built upon. (https://creativecommons.org/licenses/by-nc-nd/4.0/) \\ Georg Thieme Verlag KG, Rüdigerstraße 14, \\ 70469 Stuttgart, Germany \\ Corresponding author \\ Torsten Beyna, Evangelisches Krankenhaus Düsseldorf - \\ Department of Gastroenterology, Kirchfeldstrasse 40, \\ Düsseldorf 40667, Germany \\ Fax: +492119193960 \\ torsten.beyna@evk-duesseldorf.de
}

Cholangioscopy is increasingly used to complement to standard endoscopic retrograde cholangio-pancreatography (ERCP) as a diagnostic and therapeutic approach to biliary disorders, including biliary strictures and choledocholithiasis. Peroral cholangioscopy was first described in 1976, using a fiberoptic cholangioscope and mother-baby technique [1,2]. However, the mother-baby technique, which uses a standard duodenoscope as a platform to advance a dedicated small caliber cholangioscope into the bile duct through the working channel of the duodenoscope, has never been widely adopted in clinical routine. This was mainly due to the fragility of the baby scope, its limited maneuverability, the minute accessory channel, and the need for a second experienced endoscopist [3]. A new video cholangioscope was introduced in 1999 with high-quality digital imaging [4]. However, two experienced operators were still needed for the procedure and the problem of the fragility of the baby scope and high associated costs for repairs persisted.

In 2007, a disposable single-operator cholangioscopy (SOC) system was introduced with superior four-way deflection capabilities, eliminating the need for a second endoscopist; however, its use was limited by the low image quality provided by the fiberoptic system and the high procedural costs [5]. Basically, direct peroral cholangioscopy (DPOC) promises to merge advantages of two worlds, namely standard upper and biliopancreatic endoscopy, while enabling high-quality visualization of the biliary lumen using high-definition endoscopes with magnification capabilities and the latest image enhancement technologies, providing good maneuverability with four-way deflection of a standard ultraslim endoscope, and allowing for intraductal treatment with standard-sized accessories under op- tical control [3]. Furthermore, DPOC is a single-operator procedure and the use of a reusable endoscope may reduce the overall costs. Since 2006, DPOC has been increasingly performed using standard upper endoscopes [3, 6-8]. However, the efficacy of its clinical application is mainly determined by crucial procedural steps: (1) intubation of the papillary orifice; and (2) advancement to the region of interest and stabilization within the biliary tree. While free-hand access to the common bile duct (CBD) is cumbersome and often impossible, success rates with DPOC were significantly improved to greater than $90 \%$ by accessories and technical refinements, i. e., stiff guidewires, anchoring balloons, overtubes and other devices, that are used to enable biliary access and to stabilize the position within the bile duct, in various studies [7-11] However, application of these accessories and techniques rendered the DPOC procedure even more complex. Dedicated reusable cholangioscopes with multi-bending (MB) technology recently have been proposed to overcome these limitations and have been evaluated in clinical trials, showing high success rates for free-hand biliary access and diagnostic and therapeutic success $[3,12]$. A prospective randomized controlled trial comparing DPOC using multibending and conventional technique reported a significantly higher success rate of freehand intubation and advancement to the hilum or the obstructed segment of the bile duct, respectively, of $89.1 \%$ in the MB group compared to $30.4 \%$ in the conventional group. Remarkably, mean procedure time for MB DPOC was only 3.2 minutes. While there were reports of major complications associated with DPOC in previous trials [13], i.e. fatal gas embolism or severe cholangitis, associated with DPOC in previous trials, no such adverse events were docu- 
mented in the aforementioned trial. However, favorable results with DPOC have mainly been achieved in expert centers with broad experience in biliopancreatic endoscopy and direct peroral cholangioscopy and may not be directly transferable to other endoscopists with various levels of skill and experience $[3,12]$. In addition, application of DPOC is limited to cases with dilatation of the CBD of more than $8 \mathrm{~mm}$ and success rates with examination of the bile ducts upstream of the hilum are still inconsistent. In the last decade, single-operator cholangioscopy (SOC) has evolved from a technique requiring advanced skills with biliopancreatic endoscopy at a reference center to an easy-to-apply plug-and-play tool for direct visualization of the biliary system, thus providing high-quality digital images and therapeutic capabilities in daily care. It's efficacy in evaluation of biliary strictures and in biliary stone management have been shown in various trials [14-17]. In addition, use of disposable endoscopes may eliminate the risk of cross contamination that might be associated with reprocessable endoscopes. However, the limitation of high procedural costs remains. For complex biliary strictures, SOC is a useful tool to achieve selective guidewire insertion into the obstructed segments [18]. However, due to the minute accessory channel, the cholangioscope must be removed for stent implantation and the drainage has to be inserted without optical control.

In this context, the current retrospective feasibility trial by Park et al. in the current issue of Endoscopy International Open showed that DPOC could be used for biliary drainage by implantation of a small-caliber plastic stent or nasobiliary drainage, without exchange to a duodenoscope under visual control. The technical and clinical success rates were $100 \%$ for various indications associated with obstructive jaundice, including difficult bile duct stones and biliary strictures. Of note, inclusion criteria for the trial included dilatation of the CBD to more than $8 \mathrm{~mm}$ as well as a previously performed biliary sphincterotomy or balloon sphincteroplasty (by use of a standard duodenoscope). Because the size of the stent that can be inserted via a cholangioscope is determined by the diameter of the working channel, DPOC is unique in its ability to expand therapeutic indications for direct cholangioscopy by performing direct biliary drainage. However, the clear limitations of the study are its retrospective, uncontrolled design and the small number of patients.

While the option of direct stenting of the bile ducts without exchange of the endoscope appears attractive and may help to reduce procedural duration, questions remain to be answered about long-term efficacy and safety of these small-caliber drains (usually one 5F stent or nasobiliary drain) related to stent patency, complications related to premature stent occlusion, and the number of reinterventions necessary. Results also have to be compared with standard stenting techniques [19], preferably in prospective comparative trials. The future role of direct peroral cholangioscopy is still uncertain, despite the fact that the high technical and clinical success rates with single-operator cholangioscopy for various indications and a successful scientific approach and marketing strategy by the manufacturer of the only available system have led to worldwide use of these systems in endoscopy units that do not specialize in he- patobiliary interventions. Despite several technical improvements and available accessories, DPOC is still a challenging and cumbersome procedure and is usually performed in expert centers. Prototypes that have been shown to be effective in small single-center trials are not yet commercially available. However, there are still indications for DPOC in the diagnostic and therapeutic workup of biliary diseases in selected patients. It may remain the method of choice: 1 ) when high-resolution imaging of the CBD is needed with the option of application of advanced imaging technologies like narrow-band-imaging, magnification or artificial-intelligence-based diagnostic algorithms, i.e. in evaluation of indeterminate strictures or in the development of screening programs for premalignant lesions in the biliary system in selected high-risk patients; 2) if intraluminal therapy is needed other than biopsy or stone treatment, necessitating use of large-caliber accessories, i.e. needles or snares for EMR/polypectomy [20] or argon plasma coagulation probes; and 3) when economic resources or reimbursement policies do not allow for routine use of costly disposable cholangioscopes.

In conclusion, we have to admit that a single ideal method for cholangioscopy for each and every indication is not yet available. Currently, the choice of the optimal diagnostic and therapeutic strategy and sequence, and in particular, of the cholangioscopy method, must take into account individual patient- and procedure-related factors, including the indication for and objective of cholangioscopy, location of the target area in the biliary tree, anatomical variations, diameter of the CBD and intrahepatic bile ducts, and availability of the technology as well as local expertise and the economic burden. The majority of cholangioscopy procedures in Western countries currently are done with SOC, and DPOC is mainly performed in specialized expert centers and/or for niche indications. A first crucial step to resuscitate DPOC for wider clinical use could be to commercialize dedicated cholangioscopes with multibending technology and advanced imaging technologies at acceptable cost and create a training program for biliopancreatic endoscopists. The future role of direct peroral cholangioscopy also has to be determined by prospective clinical trials in various indications, preferably with inclusion of control groups.

\section{Competing interests}

Dr. Beyna has received consultancy and lecture honoraria from Olympus and Boston Scientific.

References

[1] Rösch W, Koch H. Peroral cholangioscopy in choledocho-duodenostomy-patients using the pediatric fiberscope. Endoscopy 1978; 10: 195-198

[2] Nakajima M, Akasaka Y, Fukumoto K et al. Peroral cholangiopancreatosocopy (PCPS) under duodenoscopic guidance. Am J Gastroenterol 1976; 66: 241-247 
[3] Beyna T, Farnik H, Sarrazin C et al. Direct retrograde cholangioscopy with a new prototype double-bending cholangioscope. Endoscopy 2016; 48: 929-933

[4] Igarashi Y, Ukita T, Inoue $\mathrm{H}$ et al. Clinical evaluation of the peroral cholangioscopy using a new videoscope. Diagn Ther Endosc 1999; 5 : 231-237

[5] Chen YK, Pleskow DK. SpyGlass single-operator peroral cholangiopancreatoscopy system for the diagnosis and therapy of bile-duct disorders: a clinical feasibility study (with video). Gastrointest Endosc 2007; 65: 832-841

[6] Larghi A, Waxman I. Endoscopic direct cholangioscopy by using an ultra-slim upper endoscope: a feasibility study. Gastrointest Endosc 2006; 63: 853-857

[7] Moon JH, Ko BM, Choi HJ et al. Intraductal balloon-guided direct peroral cholangioscopy with an ultraslim upper endoscope (with videos). Gastrointest Endosc 2009; 70: 297-302

[8] Albert JG, Friedrich-Rust M, Elhendawy M et al. Peroral cholangioscopy for diagnosis and therapy of biliary tract disease using an ultra-slim gastroscope. Endoscopy 2011; 43: 1004-1009

[9] Lenze F, Nowacki TM, Beyna T et al. Direct peroral cholangioscopy with a new anchoring technique using the guide probe of Kautz - first clinical experiences. Endoscopy 2017; 49: 909-912

[10] Choi HJ, Moon JH, Ko BM et al. Overtube-balloon-assisted direct peroral cholangioscopy by using an ultra-slim upper endoscope (with videos). Gastrointest Endosc 2009; 69: 935-940

[11] Ishida Y, Itoi T, Okabe Y. Current status and future perspective in cholangiopancreatoscopy. Curr Treatment Options Gastroenterol 2019; 17: 327-341

[12] Lee YN, Moon JH, Lee TH et al. Prospective randomized trial of a new multibending versus conventional ultra-slim endoscope for peroral cholangioscopy without device or endoscope assistance (with video). Gastrointest Endosc 2020; 91: 92-101

[13] Tringali A, Lemmers A, Meves $V$ et al. Intraductal biliopancreatic imaging: European Society of Gastrointestinal Endoscopy (ESGE) technology review. Endoscopy 2015; 47: 739-753

[14] Gerges C, Beyna T, Tang RSY et al. Digital single-operator peroral cholangioscopy-guided biopsy sampling versus ERCP-guided brushing for indeterminate biliary strictures: a prospective, randomized, multicenter trial (with video). Gastrointest Endosc 2019; 91: 11051113. doi:10.1016/j.gie.2019.11.025

[15] Navaneethan U, Hasan MK, Kommaraju K et al. Digital, single-operator cholangiopancreatoscopy in the diagnosis and management of pancreatobiliary disorders: a multicenter clinical experience (with video). Gastrointest Endosc 2016; 84: 649-655

[16] Bokemeyer A, Gerges C, Lang D et al. Digital single-operator video cholangioscopy in treating refractory biliary stones: a multicenter observational study. Surg Endosc 2019; 34: 1914-1922

[17] Turowski F, Hügle U, Dormann A et al. Diagnostic and therapeutic single-operator cholangiopancreatoscopy with SpyGlassDS'T: results of a multicenter retrospective cohort study. Surg Endosc 2018; 32: 3981-3988

[18] Bokemeyer A, Gross D, Brückner M et al. Digital single-operator cholangioscopy: a useful tool for selective guidewire placements across complex biliary strictures. Surg Endosc 2019; 33: 731-737

[19] Dumonceau JM, Tringali A, Papanikolaou IS et al. Endoscopic biliary stenting: indications, choice of stents, and results: European Society of Gastrointestinal Endoscopy (ESGE) Clinical Guideline - Updated October 2017. Endoscopy 2018; 50: 910-930

[20] Beyna T, Gerges C, Esposito I et al. Endobiliary polypectomy of biliary tumor using a prototype dedicated cholangioscope with doublebending technology. VideoGIE 2018; 3: 386-389 